\title{
Level of paranormal beliefs and its relationship with explanatory models, treatment adherence and satisfaction
}

\author{
Dushad Ram¹, Shwetha Patil 2 , Basavana Gowdappa H³ \\ 1 Department of Psychiatry, JSS Medical College and Hospital, MG Road Agrahara, Mysore \\ 2 Department of Psychiatry, JSS Medical College, Mysore, Karnataka, India. \\ ${ }^{3}$ Department of Medicine, JSS Medical College and Hospital, MG Road Agrahara, Mysore.
}

Received: 7/28/2015 - Accepted: 7/4/2016

DOI: 10.1590/0101-60830000000084

\begin{abstract}
Background: Paranormal beliefs are common among patients with mental illness. Such beliefs may mediate conceptualization of illness, treatment satisfaction and medication adherence. Objective: To study the level of paranormal beliefs and its relationship with explanatory models, treatment adherence and satisfaction using standardized assessment tool. Methods: Eighty nine patients with mental illness in remission were assessed with Sociodemographic proforma, Revised Paranormal Belief Scale (RPBS), Mental Distress Explanatory Model Questionnaire (MMAS), Morisky Medication Adherence Scale (MMAS) and Short Assessment of Patient Satisfaction (SAPS). Results: Results revealed a high level of paranormal beliefs on RPBS (Mean 83.96, SD \pm 23.91 ). Variables that had a statistically significant group difference on the score of RPBS were domicile status ( $p<05)$, diagnosis $(p<001)$, method of treatment sought before ( $<<001)$. In a linear regression analysis four variables explained $35.4 \%$ of the variance $\left(\mathrm{R} 2=.38, \mathrm{R}^{2} \mathrm{Adjusted}=.35, \mathrm{~F}=13.04, \mathrm{p}<.001\right)$ in $\mathrm{RPBS}$ Score. These variables were total score of MDEMQ $($ Beta $=.308, \mathrm{t}=3.435, \mathrm{p}<.001)$, total score of MMAS (beta $=.357, \mathrm{t}=3.716, \mathrm{p}<.001)$ and magico-religious treatment received earlier $($ beta $=.306, \mathrm{t}=3.52, \mathrm{p}<.001)$ and SAPS. Discussion: Based on the finding of this study, it may be concluded that the level of paranormal beliefs may vary with some demographic variables. Levels of paranormal beliefs is positively associated with explanatory models and adherence in patients with mental illness in remission.
\end{abstract}

Ram D et al. / Arch Clin Psychiatry. 2016;43(3):51-5

Keywords: Paranormal belief, explanatory model, patient satisfaction, medication adherence, mental illness in remission.

\section{Introduction}

Paranormal belief (PB) is the beliefs which violate currently accepted scientific theories. In India, it is common in general population and patients with mental illness; and related to evil spirits, witchcraft, astrological influences, bad deeds of previous birth and punishment for a $\sin ^{1,2}$. Few attempts have been made to explore the paranormal belief in India. Kate et al. in his study found that more than $50 \%$ of patient with schizophrenia had paranormal beliefs; particularly among males, older age, married and with lower levels of education; and initially approached to a magico-religious healers ${ }^{3}$. Swain et al. assessed the level of paranormal beliefs using revised paranormal belief scale in a small sample of patients with schizophrenia, and compared it with their siblings and controls. He observed a significant correlation of paranormal beliefs with age, gender and education ${ }^{4}$. Chakraborty et al. studied the perceptions about the cause of psychiatric disordersand subsequent help seeking 5 . A questionnaire was designed andassessed some paranormal beliefs. A high prevalence of supernatural beliefs in relatives of patients with schizophrenia (96.8\%), anxiety disorder (40\%) and depressive disorder $(27.3 \%)$ was observed. Educated patients sought more medical help (58.3\%) than illiterate and supernatural beliefs had a positive correlation with seeking of religious remedies.

In patients with mental illness, $\mathrm{PB}$ may play a role in conceptualizing their illness known as an explanatory model (EM) ${ }^{6}$. It is a socio-anthropological approach to understand the subjective experiences of distress that can be applied in psychiatric practice ${ }^{7}$. EM and PB may influence treatment adherence and satisfaction that have a bearing on the outcome of any psychiatric disorder ${ }^{8,9}$. Skeptics believe that patients with paranormal beliefs are prone to be misguided by a traditional healer which may leadto non-compliance to medication ${ }^{10}$. However, there is dearth of study that examined this issue. This study was carried out to study the level of paranormal beliefs and its relationship with explanatory models, treatment adherence and satisfaction using standardized assessment tool. We hypotheses that: 1) The level of paranormal beliefs is positively associated with explanatory models, and negatively associated with medication adherence and patients' satisfaction.

\section{Methods}

This hospital based cross sectional study was conducted at the outpatient department of psychiatry of a tertiary care general hospital in south India, after approval from the institution ethics committee. Eighty nine patients ( 40 males \& 49 females) with mental illness who were living in the community after the improvement with treatment, and came for follow-up were consecutively recruited over a period of six months after obtaining an informed consent. The inclusion criteria were: both male and female patients with a psychiatric diagnosis of axis I psychiatric disorder currently in remission as per the International Statistical Classification of Diseases and Related Health Problems, Dignostic criteria for research (ICD-10 DCR), aged 14-65 years and $>2$ consultation visits.

Patients with a comorbid chronic physical illness, diagnosis of unexplained physical complaint and involvement (self or any family member) in delivering faith or other type of healing practices were excluded from this study as they may independently influence PB, EM, patient satisfaction and treatment adherence. Patients with an ICD 10 DCR diagnosis of mental retardation and dementia were also excluded due to reliability issues. All participants were evaluated by a qualified physician and a qualified psychiatrist. Patients who satisfied the selection criteria were administered the assessment tools (Kannada translation) inthe following order:

1. Socio-demographic and clinical proforma designed for this study: this proforma assess Gender, Occupation, Religion, Education, Marital status, Family type, Domicile, Family history of mental illness, Knowledge of treatment option, Source of information, Knowledge of the course of illness, Preferred method of treatment, Referred by, and Treatment type sought before.

2. Revised Paranormal Belief Scale (RPBS) ${ }^{11}$ : this scale was used to assess the paranormal beliefs. The scale has 26 items, seven point rating (1-7) for each item, 7 subscales (Traditional religious belief, Psi, Witchcraft, Superstition, Spiritualism, Precognition, Extraordinary Life Forms) with a possible score of maximum 182 and minimum 26. The sum of all items is indicative of a general tendency to adopt a paranormal belief, while subscales can be used to measure specific dimensions of paranormal belief. 
3. Mental Distress Explanatory Model Questionnaire (MDEMQ) ${ }^{6}$ : MDEMQ was used to assess the patients' conceptualization of mental illness. This questionnaire consists of 45 items with 5 points (1-5) item rating. The items can be clustered into four explanatory categories; Western Physiology, Non-Western Physiology, Supernatural and Stress. Possible minimum score is 45 and the maximum score is 225 .

4. Morisky Medication Adherence Scale (MMAS) ${ }^{12}$ : eight items MMAS was used to assess medication adherence. Each item can be rated at 2 points $(0-1)$. Adherence is low when the score is $>2$, medium when the score is $1-2$, and high when score is 0 .

5. Short Assessment of Patient Satisfaction (SAPS) ${ }^{13}$ : SAPS was used to assess the level of satisfaction. This scale has 7 items, with a 5 point rating (0-4), and possible scores of maximum 28 and minimum of 0 . Lower score indicates less satisfaction while higher score indicate greater satisfaction.

SPSS Version 16 was used for Statistical analysis. For categorical data, frequency and percentage were used while continuous data were expressed with mean and standard deviation. After analysis of distribution of data, relationships between variables were analysed using ANOVA and linear regression analysis. For all the test significance threshold was set to $\mathrm{p}<.05$.

\section{Results}

\section{Demographic characteristics}

In this study majority of the patients were married Hindu, literate, unemployed, belonged to the urban area having anuclear family. The majority preferred the Allopathic method of treatment (mainstream medicine) and health professionals were the major source of information about their illness (Tables 1 and 2).

Table 1 reveals mean and standard deviation of scores on age, duration of illness, MDEMQ (Mean 95.44, SD \pm 22.18), MMAS (Mean 7.3, $\mathrm{SD} \pm 1.6$ ) and SAPS (Mean 8.13, $\mathrm{SD} \pm 3.58$ ).

\section{Relationship of paranormal belief with demographic and clinical variables}

Level of paranormal beliefs was analysed using descriptive statistics and ANOVA. The sample had a mean score of $83.96(S D \pm 23.91)$ on RPBS. Variables that had a statistically significant group difference on the score of RPBS were domicile status $(\mathrm{p}<.05)$, psychiatric diagnosis $(\mathrm{p}<.001)$, method of treatment sought before $(\mathrm{p}<.001)$ (Tables 1 and 2).
Relationship of paranormal belief with explanatory model, treatment satisfaction, medication adherence and demographic variables

A linear regression analysis was conducted (using the enter method) to see if any demographic variables, MDEMQ score, MMAS score and SAPS score can predict the value of RPBS (Table 3 ). Four variables explained $35.4 \%$ of the variance $\left(\mathrm{R}^{2}=.383\right.$, Adjusted $\mathrm{R}^{2}=.354, \mathrm{~F}=$ $13.044, \mathrm{df}=4, \mathrm{p}<001)$. These variables were total score of MDEMQ $($ Beta $=.308, \mathrm{t}=3.435, \mathrm{p}<.001)$, total score of MMAS (beta $=.357$, $\mathrm{t}=3.716, \mathrm{p}<.001)$ and magico-religious treatment received earlier (beta $=.306, \mathrm{t}=3.352, \mathrm{p}<.001)$ and SAPS. However the total score of SAPS did not significantly predict the value of total RPBS (beta = $-.007, \mathrm{t}=-.079, \mathrm{P}=.938)$.

A linear regression analysis was also conducted to know if subscales of MDEMQ can predict the participants' scores on RPBS (Table 4). Two subscales that explained $43.5 \%$ of the variance $\left(\mathrm{R}^{2}=\right.$ .435 , Adjusted $\left.\mathrm{R}^{2}=.408, \mathrm{~F}=16.185, \mathrm{df}=4, \mathrm{p}<001\right)$ were non-western physiology (beta $=.291, \mathrm{t}=2.269, \mathrm{p}<05)$ and supernatural subscale (beta $=.416, \mathrm{t}=3.454, \mathrm{p}<001)$.

\section{Discussion}

\section{Demographic and clinical characteristics}

We observed that the majority of patients had a preference for the allopathic method (mainstream medicine) of treatment. This was a contradictory finding to the general belief that Indians havean inclination for magico-religious treatment. Probably this reflects an increased popularity and acceptance of mainstream medicine over the years ${ }^{14-16}$ due to its higher efficacy (compared to other methods of treatment) and its role in controlling the disorders associated with high stigma in Indian culture. Medical practitioners trained in mainstream medicine are now the first caregivers than the faith healer, though in some part of India vice versa is true ${ }^{17-19}$.

\section{Level of paranormal belief}

In this study, we observed a higher level of $\mathrm{PB}(83.96, \mathrm{SD} \pm 23.91)$ as compared to other study who reported lower levels of PB (58.46, SD \pm 24.57 ) from India ${ }^{1}$. This could be due to difference in demographic characteristics and the presence or absence of mental illness in the study sample ${ }^{5}$. Dharma (as essence of eternal life, moral law and righteousness); Veda, Yoga and Sidhi (teaching of psychokinesis); and Vastushastra, Numerology, and Palmistry are supported by Indian culture that may maintain paranormal beliefs ${ }^{20-23}$.

Table 1. Clinical characteristics

\begin{tabular}{|c|c|c|c|c|}
\hline Variables & Minimum & Maximum & Mean & Std. Deviation \\
\hline Total duration of illness & 1.00 & 28.00 & 6.2 & 5.9 \\
\hline Age & 15.0 & 65.0 & 35.9 & 11.6 \\
\hline Total score on Morisky medication adherence scale & 1.0 & 8.0 & 7.3 & 1.6 \\
\hline Total score on Short Assessment of Patient Satisfaction & 2.0 & 19.0 & 8.3 & 3.3 \\
\hline Score on Mental distress explanatory model questionnaire & 59.0 & 191.0 & 95.4 & 22.1 \\
\hline Score revise paranormal belife scale & 27.0 & 121.0 & 83.96 & 23.91 \\
\hline Traditional religious belief & 6.0 & 27.0 & 18.57 & 5.21 \\
\hline Psi & 4.0 & 19.0 & 12.44 & 3.53 \\
\hline Witchcraft & 4.0 & 21.0 & 10.85 & 5.03 \\
\hline Superstition & 3.0 & 19.0 & 12.67 & 4.05 \\
\hline Spiritualism & 4.0 & 21.0 & 11.74 & 5.37 \\
\hline Precognition & 4.0 & 23.0 & 14.48 & 4.88 \\
\hline Extraordinary life forms & 1.0 & 5.0 & 1.97 & 1.26 \\
\hline
\end{tabular}


Table 2. Relationship of paranormal believe with sociodemographic \& clinical variables

\begin{tabular}{|c|c|c|c|c|c|c|c|c|c|c|}
\hline Variables & $\mathrm{n}$ & $\%$ & Mean & $\begin{array}{c}\text { Std. } \\
\text { Deviation }\end{array}$ & $\begin{array}{l}\text { Sum of } \\
\text { Squares }\end{array}$ & df & $\begin{array}{l}\text { Mean } \\
\text { Square }\end{array}$ & $\mathrm{F}$ & Sig. & $\begin{array}{c}\text { Eta } \\
\text { squaired }\end{array}$ \\
\hline $\begin{array}{l}\text { Gender } \\
\text { Male } \\
\text { Female }\end{array}$ & $\begin{array}{l}40 \\
49 \\
\end{array}$ & $\begin{array}{l}44.9 \\
55.1 \\
\end{array}$ & $\begin{array}{l}83.80 \\
84.10 \\
\end{array}$ & $\begin{array}{l}22.96 \\
24.88 \\
\end{array}$ & 2.00 & 1 & 2.00 & .003 & .953 & .000 \\
\hline $\begin{array}{l}\text { Occupation } \\
\text { Employed } \\
\text { Unemployed }\end{array}$ & $\begin{array}{l}57 \\
32 \\
\end{array}$ & $\begin{array}{l}64.0 \\
36.0 \\
\end{array}$ & $\begin{array}{l}84.00 \\
83.90 \\
\end{array}$ & $\begin{array}{l}24.82 \\
22.58 \\
\end{array}$ & .180 & 1 & .18 & .000 & .986 & 000 \\
\hline $\begin{array}{l}\text { Education } \\
\text { Illiterate } \\
\text { Primary } \\
\text { Middle } \\
\text { High school } \\
\text { Higher secondary } \\
\text { Graduate } \\
\text { Post graduate } \\
\end{array}$ & $\begin{array}{c}14 \\
11 \\
6 \\
22 \\
22 \\
12 \\
2 \\
\end{array}$ & $\begin{array}{c}15.7 \\
12.4 \\
6.7 \\
24.7 \\
24.7 \\
13.5 \\
2.2 \\
\end{array}$ & $\begin{array}{l}90.50 \\
85.27 \\
96.83 \\
78.90 \\
86.18 \\
75.66 \\
73.50 \\
\end{array}$ & $\begin{array}{c}18.26 \\
28.42 \\
22.48 \\
21.42 \\
25.42 \\
28.28 \\
4.94 \\
\end{array}$ & 3326.1 & 6 & 554.3 & .968 & .452 & .066 \\
\hline $\begin{array}{l}\text { Marital status } \\
\text { Married } \\
\text { Single/divorced/widow }\end{array}$ & $\begin{array}{l}64 \\
25 \\
\end{array}$ & $\begin{array}{l}71.9 \\
28.1 \\
\end{array}$ & $\begin{array}{l}84.48 \\
80.34 \\
\end{array}$ & $\begin{array}{l}21.05 \\
30.72 \\
\end{array}$ & 1571.6 & 2 & 785.8 & 1.387 & .255 & .031 \\
\hline $\begin{array}{l}\text { Family type } \\
\text { Nuclear } \\
\text { Joint }\end{array}$ & $\begin{array}{l}74 \\
15 \\
\end{array}$ & $\begin{array}{l}83.1 \\
16.9 \\
\end{array}$ & $\begin{array}{l}81.95 \\
93.86 \\
\end{array}$ & $\begin{array}{l}25.06 \\
13.84 \\
\end{array}$ & 1768.2 & 1 & 1768.2 & 3.169 & .079 & .035 \\
\hline $\begin{array}{c}\text { Domicile } \\
\text { Rural } \\
\text { Urban }\end{array}$ & $\begin{array}{l}36 \\
53 \\
\end{array}$ & $\begin{array}{l}40.4 \\
59.6 \\
\end{array}$ & $\begin{array}{l}91.08 \\
79.13 \\
\end{array}$ & $\begin{array}{l}20.92 \\
24.77 \\
\end{array}$ & 3062.0 & 1 & 3062.0 & 5.638 & .020 & .061 \\
\hline $\begin{array}{l}\text { Religion } \\
\text { Hindu } \\
\text { Muslim }\end{array}$ & $\begin{array}{l}75 \\
14 \\
\end{array}$ & $\begin{array}{l}84.3 \\
15.7 \\
\end{array}$ & $\begin{array}{l}83.14 \\
86.76 \\
\end{array}$ & $\begin{array}{l}24.41 \\
21.27\end{array}$ & 779.2 & 2 & 389.6 & .676 & .511 & .015 \\
\hline $\begin{array}{l}\text { Preferred treatment } \\
\text { Magico-religious } \\
\text { Allopathic }\end{array}$ & $\begin{array}{l}16 \\
73\end{array}$ & $\begin{array}{l}18.0 \\
82.0\end{array}$ & $\begin{array}{l}86.75 \\
83.35\end{array}$ & $\begin{array}{l}27.49 \\
23.21\end{array}$ & 151.1 & 1 & 151.1 & .262 & .610 & .003 \\
\hline $\begin{array}{l}\text { Psychiatric diagnosis } \\
\text { F10\&20 } \\
\text { F30 } \\
\text { F40 }\end{array}$ & $\begin{array}{l}18 \\
58 \\
13 \\
\end{array}$ & $\begin{array}{l}20.2 \\
65.2 \\
14.6 \\
\end{array}$ & $\begin{array}{l}71.51 \\
82.82 \\
69.23 \\
\end{array}$ & $\begin{array}{c}21.0 \\
21.87 \\
26.64 \\
\end{array}$ & 8320.8 & 3 & 2773.6 & 5.615 & .001 & .165 \\
\hline $\begin{array}{l}\text { Knowledge of course } \\
\text { Continuous } \\
\text { Recurrent } \\
\text { Other }\end{array}$ & $\begin{array}{c}24 \\
56 \\
9 \\
\end{array}$ & $\begin{array}{l}26.9 \\
62.9 \\
10.2 \\
\end{array}$ & $\begin{array}{l}84.91 \\
84.67 \\
75.44 \\
\end{array}$ & $\begin{array}{l}23.24 \\
23.84 \\
27.86 \\
\end{array}$ & 928.6 & 3 & 309.5 & .533 & .661 & .018 \\
\hline $\begin{array}{l}\text { Family history } \\
\text { Absent } \\
\text { Present }\end{array}$ & $\begin{array}{l}69 \\
20 \\
\end{array}$ & $\begin{array}{l}77.5 \\
22.5 \\
\end{array}$ & $\begin{array}{l}83.78 \\
84.60\end{array}$ & $\begin{array}{l}22.61 \\
28.59 \\
\end{array}$ & 10.3 & 1 & 10.3 & .018 & .894 & .000 \\
\hline $\begin{array}{l}\text { Source of information } \\
\text { Media } \\
\text { Family \& society } \\
\text { Health professionals }\end{array}$ & $\begin{array}{c}2 \\
27 \\
60 \\
\end{array}$ & $\begin{array}{c}2.2 \\
30.3 \\
67.5 \\
\end{array}$ & $\begin{array}{l}83.50 \\
83.74 \\
84.42 \\
\end{array}$ & $\begin{array}{l}17.67 \\
22.16 \\
25.19 \\
\end{array}$ & 412.8 & 3 & 137.6 & .234 & .872 & .008 \\
\hline $\begin{array}{l}\text { Knowledge of treatment option } \\
\text { Pharmacological only } \\
\text { Pharmacological \& } \\
\text { Psychological } \\
\text { Magico-religious } \\
\text { Ayurvedic }\end{array}$ & $\begin{array}{c}64 \\
21 \\
3 \\
1 \\
\end{array}$ & $\begin{array}{c}71.9 \\
\\
23.6 \\
3.4 \\
1.1 \\
\end{array}$ & $\begin{array}{l}85.85 \\
78.04 \\
89.66 \\
70.00 \\
\end{array}$ & $\begin{array}{l}22.58 \\
27.56 \\
29.28\end{array}$ & 1257.5 & 3 & 419.1 & .726 & .539 & .025 \\
\hline $\begin{array}{l}\text { Referred by } \\
\text { Self } \\
\text { Family members } \\
\text { Health professionals }\end{array}$ & $\begin{array}{l}15 \\
60 \\
14 \\
\end{array}$ & $\begin{array}{l}16.9 \\
67.4 \\
15.7 \\
\end{array}$ & $\begin{array}{l}78.40 \\
87.36 \\
80.50 \\
\end{array}$ & $\begin{array}{l}27.89 \\
21.15 \\
29.44 \\
\end{array}$ & 2344.2 & 3 & 781.4 & 1.385 & .253 & .047 \\
\hline $\begin{array}{l}\text { Method of treatment sought before } \\
\text { Magico-religious } \\
\text { Allopathic } \\
\text { Ayurvedic }\end{array}$ & $\begin{array}{c}38 \\
49 \\
2\end{array}$ & $\begin{array}{c}42.7 \\
55.1 \\
2.2\end{array}$ & $\begin{array}{l}96.39 \\
74.08 \\
90.00\end{array}$ & $\begin{array}{c}18.58 \\
23.62 \\
4.24 \\
\end{array}$ & 10730.1 & 2 & 5365.0 & 11.658 & .000 & .213 \\
\hline
\end{tabular}


Table 3. Relationship of paranormal belief with explanatory model, treatment satisfaction, medication adherence

\begin{tabular}{|l|l|c|c|c|c|c|}
\hline \multirow{2}{*}{ Model } & Variables & \multicolumn{2}{|c|}{$\begin{array}{c}\text { Unstandardized } \\
\text { Coefficients }\end{array}$} & \multicolumn{2}{|c|}{$\begin{array}{c}\text { Standardized } \\
\text { Coefficients }\end{array}$} \\
\cline { 3 - 7 } & & B & Std. Error & Beta & t \\
\hline 1 & (Constant) & 3.470 & 14.674 & & .236 & .814 \\
\hline & Magico-religious treatment received & 14.725 & 4.392 & .306 & 3.352 & .001 \\
\hline & Total MDEM0 score & .332 & .097 & .308 & 3.435 & .001 \\
\hline & Total MMAS score & 1.971 & .530 & .357 & 3.716 & .000 \\
\hline & Total SAPS score & -.049 & .624 & -.007 & -.079 & .938 \\
\hline
\end{tabular}

$\mathrm{R}^{2}=.383$, Adjusted $\mathrm{R}^{2}=.354, \mathrm{~F}=13.044, \mathrm{df}=4, \mathrm{p}<001$.

Dependent variable $=$ RPBS Score.

Table 4. Relationship of paranormal belief with subscales of MDEMO

\begin{tabular}{|c|c|c|c|c|c|c|}
\hline \multirow[t]{2}{*}{ Model } & \multirow[t]{2}{*}{ Variables } & \multicolumn{2}{|c|}{$\begin{array}{c}\text { Unstandardized } \\
\text { Coefficients }\end{array}$} & \multicolumn{2}{|c|}{$\begin{array}{c}\text { Standardized } \\
\text { Coefficients }\end{array}$} & \multirow[t]{2}{*}{ Sig. } \\
\hline & & $B$ & Std. Error & Beta & $t$ & \\
\hline \multirow[t]{5}{*}{1} & (Constant) & 69.170 & 8.991 & & 7.694 & .000 \\
\hline & Stress & -.473 & .253 & -.199 & -1.874 & .064 \\
\hline & Western Physiology & -.551 & .522 & -.121 & -1.056 & .294 \\
\hline & Non-Western Physiology & 3.172 & 1.398 & .291 & 2.269 & .026 \\
\hline & Supernatural & .738 & .214 & .416 & 3.454 & .001 \\
\hline
\end{tabular}

$\mathrm{R}^{2}=.435$, Adjusted $\mathrm{R}^{2}=.408, \mathrm{~F}=16.185, \mathrm{df}=4, \mathrm{p}<001$.

Dependent variable $=$ RPBS Score.

The result revealed that domicile status had a group difference on the score of RPBS. In comparison with rural, urban status gives an ample opportunity for education and exchange of scientific information that help people to update their knowledge and modify their belief 1,24 . We observed that diagnosis had a significant group difference on the score of RPBS. This finding has some similarity with the observation made by others, who reported variation in belief with the diagnosis ${ }^{5,25}$. In the absence of evidence of cause (as seen with physical disease), people tend to attribute supernatural forces for symptoms of mental illness, and such beliefs are maintained by prevalent witch doctors in rural India ${ }^{24}$. Group difference on the score of RPBS was also observed with the type of treatment received in the past for the mental illness. The majority of the participants had received mainstream treatment (Allopathic), magico-religious and Ayurvedic method of treatment before participating in this study. This finding is congruent with common explanatory models prevailing in Indian about an illness (medical and supernatural model) ${ }^{3,26,27}$. It appears that depending upon the explanatory model of illness, patients sought a treatment method ${ }^{26}$. Those with a medical model continued with the next level of treatment (primary care to tertiary care) while those with non-medical model changed their strategy and shifted to the medical model after an inadequate response to the treatment ${ }^{19}$.

\section{Relationship of paranormal belief with explanatory model, treatment satisfaction, medication adherence and demographic variables}

Consistent with our hypothesis, the level of paranormal beliefs had a significant positive association with Non-Western Physiology \& Supernatural subscales of MDEMQ in this study. This may be because both are rooted in the collective explanatory model (a model shared by most members of the Indian community). PB explains mostly personalistic cause (e.g. religious, supernatural) while MEMQ explains both personalistic and naturalistic causes (situations, psychobiological). Indians attribute more of a personalistic cause such as God's will, supernatural force and astrological cause for suffering or problems ${ }^{28}$. Prevalent astrological beliefs such as Shani (Saturn), Rahu (the ascending node of the moon) and Ketu (descending node of the Moon) is often believed to determine good or bad happening in daily life. Ayurveda, an ancient method of treatment (that is prevalent in India since centuries) describes three types of life forces (tridoshas): pitta dosha (fire and water), kapha dosha (water and earth) and vata dosha (space and air). Excited Vayu (gas) of the vata dosha has been mentioned as causes of mental illness ${ }^{29,30}$. Some disorder such as Dev-unmada (psychological disturbances due to God), Bhoot-unmada (due to ghost) described in Ayurveda attributes supernatural force as the cause of mental illness ${ }^{30}$. Other indigenous method of treatment such as faith healing \& Jadi-Buti also supports the supernatural cause of mental illness. Lagna and Raasi are common horoscopic supernatural factors often attributed to determine the health, fortune or misfortune depending upon the astrological status, such as the position of planets \& the moon $^{31}$. The significant association (positive) of the past magicoreligious treatment and paranormal belief indicates the congruence of belief and treatment.

Consistent with our hypothesis, we found a statistically significant negative association of paranormal belief with medication adherence. This is consistent with other reports, that supernatural belief is associated with unfavorable compliance ${ }^{26,32}$. Those who subscribe to a supernatural cause of mental illness, their decision to continue medication may be influenced by belief, they may have a negative attitude toward medication, and more likely to go with the idea that magicoreligious rituals are helpful 2,3 . Since medical treatment is based on the medical model of illness, which may not go with a patient's model of illness the patient may be less adherent to medication.

We could not find any association of paranormal believe and satisfaction, and this is not consistent with our hypothesis. Possible reason could be that patient's belief alone may not determine the satisfaction, but other factors such as doctor patient relationship, quality of service provided and improvement in symptoms are important determinants of satisfaction ${ }^{33}$. 


\section{Conclusion}

Based on the finding of this study, it may be concluded that level of paranormal beliefs varies with some demographic variables. Levels of paranormal believes is positively associated with non-western physiology and supernatural dimension of explanatory models and negatively associated with adherence in patients with mental illness in remission availing services at tertiary care.

Though our hypothesis appears to be partly true, this study finding should be interpreted in the context of Indian culture. The limitations of this study were a heterogenous patient group, no control population for comparison, small sample size; purposive sampling method and knowledge about the illness was not assessed (especially biomedical model). Further studies are needed to address the limitations of this study.

\section{Acknowledgement}

Authors would like to thank Yahosa, Shamaya, Hagai, Asther, Yasuas, Marias, Ashish, Akash and Mini for their moral help.

\section{Conflict of interest}

Nil.

\section{References}

1. Ali A, Deuri SP, Jahan M. Paranormal belief among school and college going students. Global Res Ana. 2013;2(4):231-2.

2. Kishore J, Gupta A, Jiloha RC, Bantman P. Myths, beliefs and perceptions about mental disorders and health-seeking behaviour in Delhi, India. Indian J Psychiatry. 2011;53:324-9.

3. Kate N, Grover S, Kulhara P, Nehra R. Supernatural beliefs, aetiological models and help seeking behaviour in patients with schizophrenia. Indian J Psychiatry. 2012;21:49-54.

4. Swain MR, Das B, Bhattacharjee D. Magical thinking and paranormal beliefs among the siblings of patients with schizophrenia. Indian J Soc Psychiatry. 2012;28(1-2):60-6.

5. Chakraborty K, Das G, Dan A, Bandyopadhyay G, Chatterjee M. Perceptions about the cause of psychiatric disorders and subsequent help seeking patterns among psychiatric outpatients in a tertiary care centre in eastern India. German J Psychiatry. 2013;16(1):7-14.

6. Eisenbruch M. Classification of natural and supernatural causes of mental distress: development of a Mental Distress Explanatory Model Questionnaire. J Nerv Ment Dis. 1990;178(11):712-9.

7. Bhui K, Bhugra D. Explanatory models for mental distress: implications for clinical practice and research (editorial). Br J Psychiatry. 2002;181:6-7.

8. Callan A, Littlewood R. Patient satisfaction: ethnic origin or explanatory model? Int J Soc Psychiatry. 1998;44:1-11.

9. Barbosa CD, Balp MM, Kulich K, Germain N, Rofail D. A literature review to explore the link between treatment satisfaction and adherence, compliance, and persistence. Patient Prefer Adherence. 2012;6:39-48.

10. Hines T. Pseudoscience and the paranormal. 2nd ed. Amherst, NY: Prometheus, 2003.

11. Tobacyk JJ. A Revised Paranormal Belief Scale. Int J Transper Stu. 2004;23:94-8.

12. Morisky DE, Green LW, Levine DM. Concurrent and predictive validity of a self-reported measure of medication adherence. Medical Care. 1986;24:67-74.
13. Sansoni J, Hawthorne G, Marosszeky N, Moore K, Fleming G,et al. Validation and clinical translation of the revised continence and patient satisfaction tools: Final report. Centre for Health Service Development, University of Wollongong, 2011.

14. Sharma NK, Agrawal MA, Agarwal AK, Sharma A, Verma H, et al. General awareness on allopathic, ayurvedic and homeopathic system of medicine in Chhattisgarh, India.Int J Pharm Pharmaceut Sci. 2011;4(3):159-62.

15. Jawla S, Gupta K, Singla R, Gupta V. General awareness and relative popularity of allopathic, ayurvedic and homeopathic systems. J Chem Pharmaceut Res. 2009;1(1):105-12.

16. Bagadia VN, Shah LP, Pradhan PV, Gada MT. Treatment of mental disorders in India. Prog Neuropsychopharmacol. 1979;3(1-3):109-18.

17. Faizan S, Raveesh BN, Ravindra LS, Sharath K. Pathways to psychiatric care in South India and their socio-demographic and attitudinal correlates. BMC Proceedings. 2012;6(4):13.

18. Jain N, Gautam S, Jain S, Gupta ID, Batra L, Sharma R, et al. Pathway to psychiatric care in a tertiary mental health facility in Jaipur, India. Asian J Psychiatry. 2012;5(4):303-8.

19. Lahariya C, Singhal S, Gupta S, Mishra A. Pathway of care among psychiatric patients attending a mental health institution in central India. Indian J Psychiatry. 2010;52:333-8.

20. Juthani, NV. Understanding and treating Hindu patients. In: Koenig HG (Ed.), Handbook of religion and mental health. New York: Academic Press; 1998. p. 271-8.

21. Braud W. Patanjali Yoga and siddhis: their relevance to parapsychological theory and research. In: Rao KR, Paranjpe AC, Dalal AK (eds.). Handbook of Indian psychology. New Delhi, India: Cambridge University Press (India) Foundation Books; 2008. p. 207-43.

22. Padmanabhan RA. Matching of Horoscope. Astro Mag. 1986;75(1):73-8.

23. Judy FP. Astrological counseling in contemporary India. Cul Med Psychiatry. 1983;7:279-99.

24. Davies O. Urbanization and the decline of witchcraft: An Examination of London. J Soc Hist. 1997;30(3):597-617.

25. Soh KC, Lee C, Ng BY, Chee KT. A Revisit to Paranormal Beliefs - When Is It A Psychiatric Disorders? Asean J Psychiatry. 2011;12(2):178-89.

26. Sharif SA, Ogunbanjo GA. Reasons for non compliance to treatment among patients with psychiatric illness: a qualitative study. South Afr Fam Pract. 2003;45:10-3.

27. Nambi SK, Prasad J, Singh D, Abraham V, Kuruvilla A, Jacob KS. Explanatory models and common mental disorders among patients with unexplained somatic symptoms attending a primary care facility in Tamil Nadu. Natl Med J India. 2002;15:331-5.

28. Conrad MM, Pacquiao DF. Manifestation, attribution, and coping with depression among Asian Indians from the perspectives of health care practitioners. J Transcult Nur. 2005;16(1):32-40.

29. Ramu MG, Venkataram BS. Manovikara (Mental disorders) in Ayurveda. Anc Sci life. 1985;4(3):165-73.

30. Acharya YT. Charaka samhita. Commentary of Chakrapani. Nirnayasagar Press, Bombay; 1941.

31. Padhy S, Dash KK, Padmavati A. Astro-ethnobiology: II the astrological basis of human characters - An ecological imperative. J Human Eco. 2005;17(4):263-76.

32. Razali SM, Khan UA, Hasanah CI. Belief in supernatural causes of mentalillness among Malay patients: impact on treatment. Acta Psychiatr Scand. 1996;94(4):229-33.

33. Pearse, J. 'Review of patient satisfaction and experience surveys conducted for public hospitals in Australia - A Research paper for the Steering Committee for the Review of Government Service Provision', June 2005. 